\section{DIGITAL COMMONS \\ @ UNIVERSITY OF SOUTH FLORIDA}

\section{ABO: Interactive Journal for Women in the Arts, 1640-1830}

\title{
Writing With Aphra: Solidarity, Generosity, and Fight Club Rules Beyond Summer 2020
}

\author{
Kirsten T. Saxton \\ Mills College, ktsaxton@mills.edu \\ Bethany E. Qualls \\ University of California, Davis, bequalls@ucdavis.edu
}

Follow this and additional works at: https://digitalcommons.usf.edu/abo

Part of the Dramatic Literature, Criticism and Theory Commons, Educational Methods Commons, Feminist, Gender, and Sexuality Studies Commons, and the Literature in English, British Isles Commons

\section{Recommended Citation}

Saxton, Kirsten T. and Qualls, Bethany E. (2021) "Writing With Aphra: Solidarity, Generosity, and Fight Club Rules Beyond Summer 2020," ABO: Interactive Journal for Women in the Arts, 1640-1830: Vol.11: Iss.1, Article 17. http://doi.org/10.5038/2157-7129.11.1.1266

Available at: https://digitalcommons.usf.edu/abo/vol11/iss1/17

This Conversation is brought to you for free and open access by Digital Commons @ University of South Florida. It has been accepted for inclusion in ABO: Interactive Journal for Women in the Arts, 1640-1830 by an authorized administrator of Digital Commons @ University of South Florida. For more information, please contact digitalcommons@usf.edu. 


\title{
Writing With Aphra: Solidarity, Generosity, and Fight Club Rules Beyond Summer
} 2020

\author{
Abstract \\ A short piece in praise of the summer Write With Aphra program for pandemic support of women and non \\ binary writers and a discussion of how the program is useful beyond its original parameters \\ Creative Commons License \\ (c) (i) (9)
}

This work is licensed under a Creative Commons Attribution-Noncommercial 4.0 License 
Our small summer 2020 \#WriteWithAphra group was inspired by the generous, open, authentic community of care modeled in the writing camp's larger meetings: the goal was transparency and sharing information and demystification, no stupid questions and lots of brass tacks. In fact, it was such a hit, we decided to keep the party going after the official $A B O$ program ended, and it is still going strong today with virtual writing groups, weekly emails, and social meetings.

\section{How this all started}

ABO's 2020 summer writing accountability community, \#WriteWithAphra, asked its editors and board to "commit time to help foster scholarship in progress and to provide a structure to improve its chances of timely publication." The summer program was a powerful model of feminist praxis in action and exemplifies the journal's commitment to publishing work that "interrogates and reveals the causes, histories, and narratives of the harmful intersections of patriarchy, sexism, racism, slavery, colonialism, and gender discrimination." Weekly large group meetings offered substantive content on topics from publishing your first article to support sessions for BIPOC scholars, as well as beautifully curated notes, links, and handouts put together by Dr. Kate Ozment.

All 125 participants in $A B O$ 's virtual writing accountability community were randomly assigned to a smaller group run by an $A B O$ editor or board member, where people could check in via email and/or a casual, weekly Zoom drop-in office hour. Kirsten led our small group of 15 that was very much a microcosm of the overall group: a mix of people in different stages of their careers, with different academic backgrounds and fields, in different geographical locations, of different ages, races, nationalities. In our group, everyone identified as a woman, and most folks came to the summer program from long 18th-century literary or history sites, though some from other academic areas saw the tag on Twitter and joined that way.

In these Zoom rooms and email threads, first-year graduate students and professors emerita shared the same space and access to conversation and mentoring; conversations were generous, specific, and moved with ease as all questions were treated seriously and with care, and anyone with specific advice or knowledge shared it. For the group at large, a seasoned editor offered advice on 
how to write a cover letter when turning in revisions after a revise and resubmit, folks with access offered to get article copies for those who could not access their libraries, tech savvy members shared online research tools, and people readily offered to read material, shared time management hacks, offered solidarity in the despair and rage of the situations one cannot self-manage or lifehack one's way out of: those harmful intersections of racism, nationalism, sexism, late capitalism, and imperialism that were pressing on all of us in varying ways to varying degrees. This was a group that acknowledged the structural nature of the issues we face, and successfully resisted the nasty tendencies of productivity discourse, to focus instead on community and praxis, a sort of mutual aid for academics, that included awareness of limited resources and shared expertise.

In response to interest from members across the small groups for virtual shared writing space, Bethany set up co-writing sessions open to all \#WriteWithAphra members. A doodle poll and lots of emails later, those interested could meet on Zoom at set times and check in, then work for a set time, and check in afterwards about what happened. Some people did this every day, others once or twice a week. It helped give structure to what would often be nebulous work time and a feeling of never getting enough done.

\section{What our small group did}

Meanwhile, Bethany quickly made a listserv (named \#WriteWithAphra Team Kirsten) to streamline our communication with group members, and Kirsten started a weekly email discussion on the theme of the week and our writing goals and challenges. Our group included graduate students, post docs, every rank of professor; we zoomed in from France, Texas, London, California, Michigan, New York, and more. Our small group weekly email check-ins also included personal questions, such as favorite current ways to decompress/disassociate, what was hardest thing about the week, our weekly "wins" in writing but also survival, a question for the group, etc. In addition, our group met weekly on Zoom. Folks were welcome to drop in and out of the Zooms and the emails. It was very much a "do what serves you, and don't feel guilty if it is not a good week to come" vibe.

\#WriteWithAphra Team Kirsten shared everything from cocktail recipes to frustrations with dissertation committees, challenges in caregiving for family 
members or institutions ignoring the realities of COVID-19 to successfully writing at least 15 minutes for multiple days in a row. While the original plan was that the groups would wrap up in summer, we enjoyed them so much that Kirsten offered to keep it going, if Bethany would come on as co-host and organizer. People from other \#WWA small groups joined, and we have been meeting and emailing weekly with our 25 members ever since.

The writing groups have also continued, and a collectively written piece about the progress and process of these sessions orchestrated by group member Ashley Bender is forthcoming.

\section{A shift in modes and looking forward}

Reflecting on why this continued support has been so helpful, we see that the \#WriteWithAphra weekly check-ins replicate the best of casual connection at conferences without the exclusionary practices. They are free spaces: no one is making moves on you or trying to take you down. They invite a structured openness of people across ranks and places. We're talking about ideas, sharing work, and also sharing challenges instead of pretending everything is fine. Another great impact has been seeing the collegial relationships deepen as people read each other's work, offer source ideas, and act as sounding boards for everything from article revisions to book proposals. We also love celebrating one another for small and large wins and all in between! Reading and talking about pleasures as well as challenges allows us access to a sense that all is not terrible, and we truly are over the moon when someone passes their comps! Or gets that article in! Or sleeps a full night! We showed off cats, moving boxes, and holiday onesies as well as writing tips. Some members even got mugs (inspired by Kelly Plante's design showcasing images of awesome eighteenth-century women writers including Aphra Behn) that still show up during meetings or writing sessions. More merch ideas are in the works. 
Furthermore, the open, social casual connections have helped in these COVID times where casual social contact is hard to come by. The Fight Club style rules of what happens in these groups stays there means people feel seen and cared for. We are a safe space for the tricky stuff. The causal nature means you don't feel guilty if you skip meetings or never come to them at all. You know that people are available and how to reach them. It's really the praxis of care work — of writing and thinking together as a community. People will continue to be spread out, with complex access to travel and in-person gathering, and this sort of group provides greater more flexible access, with less exclusive sociability.

The program provided boundaries and accountability for scholarly production as well as connection that mitigated isolation and provided material help. \#WriteWithAphra extended the editorial foundational belief that led to $A B O$ s founding: that rigor and scholarship are not only possible but are better when the community values vulnerability and inclusion of the whole self. We need to continue to call in our communities, our whole selves, to create academic spaces

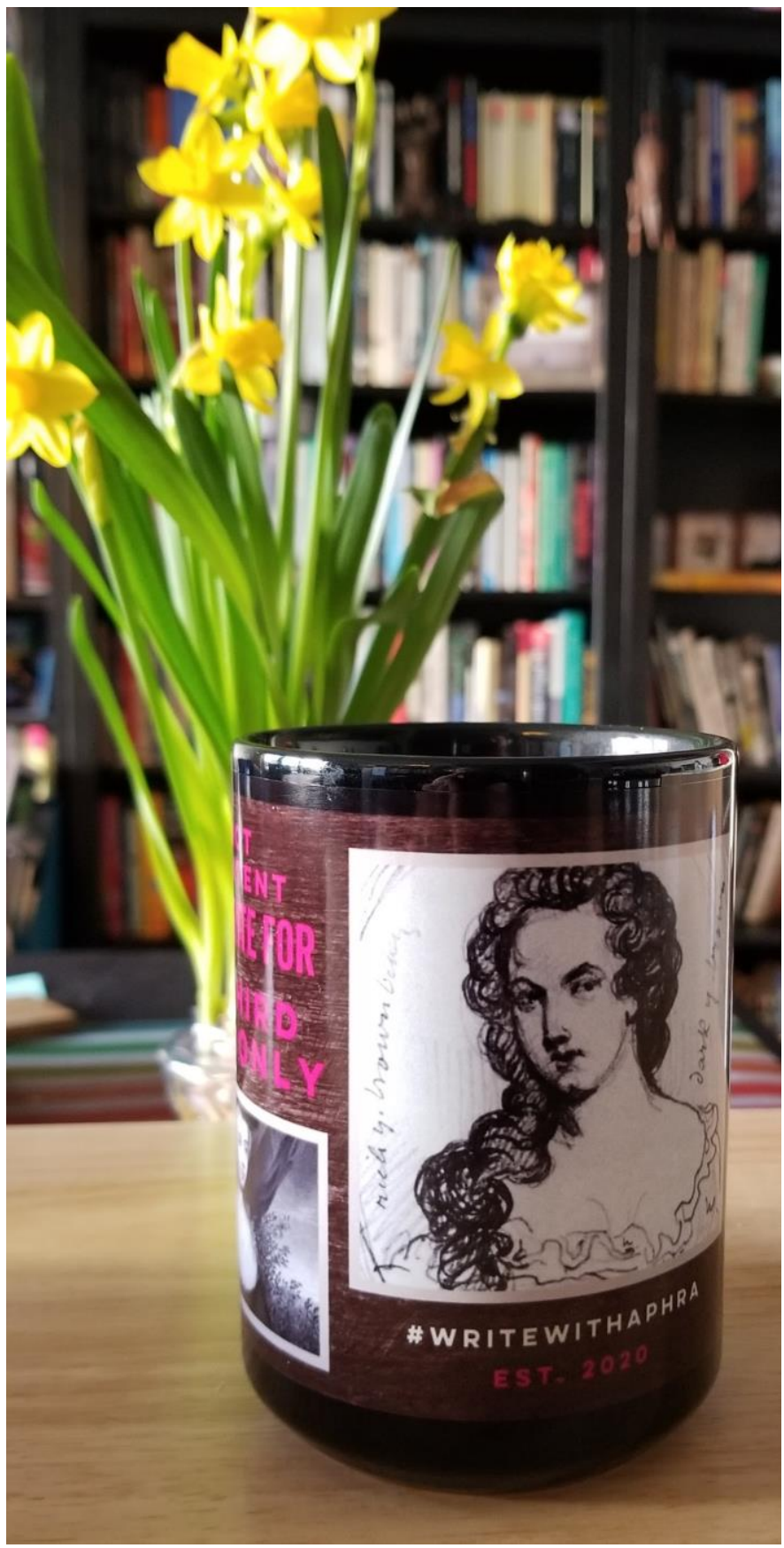
that offer opportunities for writing, reading and thinking, not despite but through, loss and grief, wry humor, disassociation tactics, material support, and affectionate delight. And frankly? 
We'll take moments of shared delight and actual mutual aid over academic messages that rehash the fraught and fragile nature of "these uncertain times," while offering no actual support, any day of the week. 